\title{
NEAR-OPTIMAL LEVELS OF 2,4-DICHLOROPHENOXYACETIC ACID AND INDOLE ACETIC ACID FOR IN-VITRO DIRECT REGENERATION OF SHOOTS FROM SUGAR- CANE (Saccharum spp. Hybrid) LEAF TISSUES
}

\author{
DN Balagalla $^{1 *}$, A Wijesuriya $^{1}$, NP Ranathunge ${ }^{2}$ and AMMS Perera ${ }^{1}$ \\ ${ }^{1}$ Sugarcane Research Institute, Uda Walawe, Sri Lanka \\ ${ }^{2}$ Department of Agricultural Biology, Faculty of Agriculture, University of Ruhuna, Mapalana, Kam- \\ burupitiya, Sri Lanka
}

Accepted: $1^{\text {st }}$ September 2016

\begin{abstract}
Four combinations with two levels of each 2,4-Dichlorophenoxyacetic Acid (2,4-D) (0.2 mg/L, 0.5mg/L) and Indole Acetic Acid (IAA) (1mg/L, 4mg/L) together with $0.1 \mathrm{mg} / \mathrm{L}$ of Kinetin and $40 \mathrm{mg} / \mathrm{L}$ of Cysteine Hydrochloride determined by testing their 150 combinations for in-vitro direct shoot regeneration from sugarcane (Saccharum spp. Hybrid) leaf tissues were further evaluated using the variety SL 96328 in a completely randomised layout with 30 replicates to find out their near-optimal levels. Leaf spindle slices of the sugarcane variety SL 96328 was used as ex-plants for culture in the modified MS medium. After 3 weeks of culture, the survival of ex-plants and the number of shoots directly regenerated from ex-plants were recorded in one-week intervals. The concentration of $0.5 \mathrm{mg} / \mathrm{L}$ of $2,4-\mathrm{D}$ and $1 \mathrm{mg} / \mathrm{L}$ of IAA together with $0.1 \mathrm{mg} / \mathrm{L}$ of Kinetin and $40 \mathrm{mg} / \mathrm{L}$ of Cysteine Hydrochloride regenerated the highest number of viable shoots from leaf spindle discs after 4 weeks of culture. On average, 21 shoots were obtained from a leaf spindle disc of $2 \mathrm{~mm}$ thickness and $3 \mathrm{~mm}$ in diameter obtained from sugarcane plants of 5- to7- month old.
\end{abstract}

Key words: 2,4-Dichlorophenoxyacetic Acid, Direct Shoot Regeneration, Indole Acetic Acid, In-vitro Culture, Kinetin, Sugarcane

\section{INTRODUCTION}

Non-availability of good-quality planting material at the correct time of planting has been one of the main constraints for increasing productivity in sugarcane cultivation in Sri Lanka. Even though new high-yielding varieties have been introduced for commercial cultivation, the average sugarcane yields in commercial sugarcane plantations and the sugar recovery rates in sugar mills have remained stagnated (Ehsanullah et al., 2011, Annon., 2015). Apart from the non-availability of planting material of the new sugarcane varieties, one of the main reasons for this situation is varietal degeneration due to accumulation of systemic diseases in the plant over the years as sugarcane is propagated vegetatively (Viswanathan, 2016). Mass production of genetically-pure and disease-free planting material of new improved varieties recommended for commercial cultivation by the Sugarcane Research Institute (SRI) has become an essential requirement for increasing productivity of sugarcane lands.
Furthermore, use of good-quality sugarcane planting material in commercial fields has become mandatory with the enforcement of Seed Act of 2003 in Sri Lanka (http:// www.doa.gov.1k/images/stories/site/PDF/ Acts/seed\%20act.pdf). Therefore, production of disease-free and genetically-pure seed-cane in required quantities at a rapid rate and lesser cost has become an important necessity for the expansion of the sugar industry in Sri Lanka and increasing its productivity and profitability.

In this scenario, in addition to new planting, replacement of the disease-infected degenerated old sugarcane plantations with diseasefree pure new sugarcane varieties is required. Rapid propagation of the planting material of new sugarcane varieties has to be undertaken to meet this requirement. Lateral shoot multiplication and meristem culture can be used to propagate sugarcane planting material at a rapid rate (Wijesuriya et al., 2001). In addition, direct regeneration of plants from in- 
vitro-cultured young leaf segments of sugarcane is one of the superior methods for rapid propagation at a lesser cost as it possess 8- to 10 -fold multiplication rate than meristem culture (Lakshmanan et al., 2006). Lakshmanan et al. (2006) and Mittal et al. (2013) reported that in-vitro direct plant regeneration technology from leaf spindle tissues of sugarcane could be used for production of geneticallyidentical plants at higher multiplication rate and at a lesser cost per plant. The percentage of shoot organogenesis was reported to vary with the variety (Mittal et al., 2013).

To generate plants from sugarcane leaf spindle tissues, determination of the optimum size of the ex-plants and the conditions of the ex-plant culture medium are required. The investigations on auxin and cytokinin concentrations in culture media and the culture conditions by Lakshmanan et al. (2006) and Khan et al. (2009) have shown some promising protocols for this technique. This research was, therefore, carried out to find out the near-optimal levels of plant growth regulators, namely, 2,4Dichlorophenoxyacetic Acid $(2,4 \mathrm{D})$ and Indole Acetic Acid (IAA) for in-vitro direct shoot regeneration from leaf spindle tissues of sugarcane as the first step of developing a tissue culture protocol for producing geneticallyidentical plants to the mother plants superseding the callus phase in culture.

\section{MATERIALS AND METHODS}
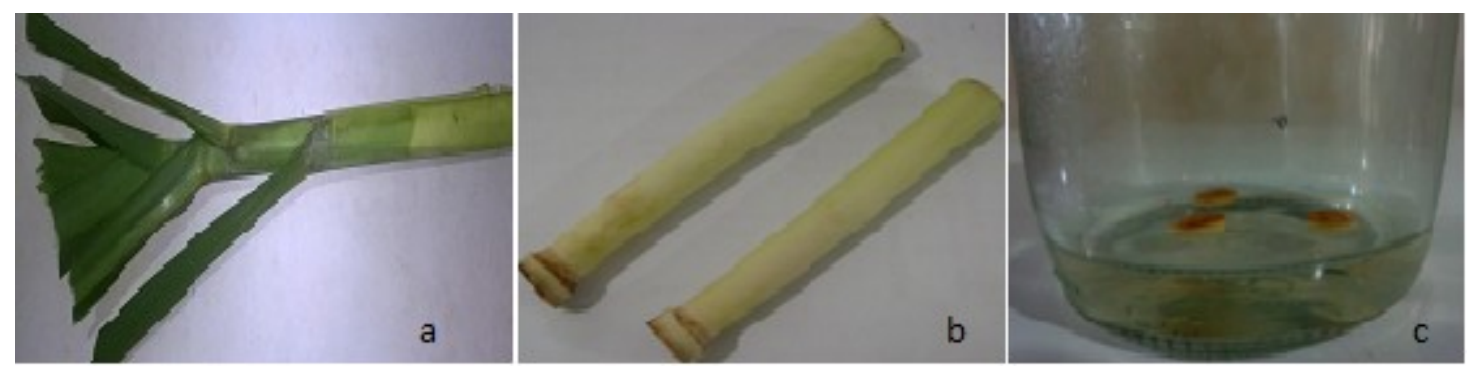

The newly-introduced commercial sugarcane variety SL 96328 (Saccharum spp. Hybrid) was used in this study since there is high demand for planting material of this variety from sugar companies. Cane tops with leaf spindle region (Figure 1a) were collected from 5- to 7month-old meri-clonned sugarcane (Saccharum spp. Hybrid) plants grown in the poly-house of the Sugarcane Research Institute, Uda Walawe. Leaf spindle pieces of about $10 \mathrm{~cm}$ length (Figure 1b) were obtained at the laboratory by stripping off mature leaf sheaths. They were washed several times with running tap water and sterilized with $70 \%$ alcohol. All microbial decontamination procedures were performed in a laminar air flow hood. The outer cover of the spindle pieces formed by leaf sheaths was removed carefully without damaging the inner young and delicate tissues. Thirty slices of leaf spindles (ex-plants) with $2 \mathrm{~mm}$ thickness and $3 \mathrm{~mm}$ in diameter were cultured in the modified Murashige and Skoog (MS) medium containing different combinations of Auxins and Cytokinins (Figure 1c). One hundred and fifty combinations of Kinetin, 2,4Dichlorophenoxyacetic Acid (2,4-D) and Indole Acetic Acid (IAA) were tested initially for direct shoot regeneration without forming calli. The four hormone combinations with 2,4-D 0.5 and $0.2 \mathrm{mg} / \mathrm{L}$ and IAA 0.1 and $0.4 \mathrm{mg} / \mathrm{L}$ together with Cysteine Hydrochloride $40 \mathrm{mg} / \mathrm{L}$ and Kinetin $0.1 \mathrm{mg} / \mathrm{L}$ were found to give promising results on direct shoot regeneration from leaf tissues. Initially, the cultures were kept in the dark for 2 weeks, and then transferred to air-

Figure 1: Different steps of explants preparation a) Cane tops with leaf spindle region. b) Leaf spindle pieces. c) Ex-plants with $2 \mathrm{~mm}$ thickness in culture 
conditioned culture room with white inflorescence light with an intensity of $2-3 \mathrm{klx}$. The addition of Cysteine Hydrochloride at concentration of $40 \mathrm{mg} / \mathrm{L}$ was to avoid browning of the media due to accumulation of phenolic compounds. These four combinations of 2,4$\mathrm{D}$ and IAA were further tested using $30 \mathrm{ex}$ plants (replicates), and the cultures were arranged in a completely randomised layout.

\section{Data}

After three weeks of culturing the ex-plants, survival of the cultured ex-plants was determined by the number of progressive explants. The number of shoots directly regenerated from the ex-plants was recorded in one -week intervals commencing from the $3^{\text {rd }}$ week until the $8^{\text {th }}$ week of culture.

\section{Data analysis}

The percentage survival of the ex-plants at different hormone combinations was calculated and was presented graphically (Figure 3 ). The analysis was done on the survival of the ex-plants (culture success) from 3 weeks to 8 weeks of culture. Development of embryo -like structures was observed by the presence of somatic embryos on the cultured ex-plants in all treatments tested (D-1, D-2, D-3 and D4) (Table 1). Shoots were observed only in D1 medium therefore, the mean number of shoots developed from 30 ex-plants in culture in the D-1 treatment was taken as the number of shoots directly regenerated from an explant.

\section{RESULTS AND DISCUSSION}

The ex-plants in the first 3 weeks of the culture in all the tested media (Table 1) showed swelling and initiation of small embryo-like structures (Figure 2a). However, welldeveloped embryo-like structures were ob-

Table 1: Combinations of Kinetin, 2,4-D and IAA levels tested for direct plant regeneration

\begin{tabular}{lllll}
\hline Treatment & Kinetin $(\mathrm{mg} / \mathrm{L})$ & $2,4-\mathrm{D}(\mathrm{mg} / \mathrm{L})$ & IAA $(\mathrm{mg} / \mathrm{L})$ & $\begin{array}{l}\text { Cysteine } \\
\text { Hydrochloride }(\mathrm{mg} / \mathrm{L})\end{array}$ \\
\hline $\mathrm{D}-1$ & 0.1 & 0.5 & 1.0 & 40 \\
$\mathrm{D}-2$ & 0.1 & 0.5 & 4.0 & 40 \\
$\mathrm{D}-3$ & 0.1 & 0.2 & 1.0 & 40 \\
$\mathrm{D}-4$ & 0.1 & 0.2 & 4.0 & 40 \\
& & & & \\
\hline
\end{tabular}

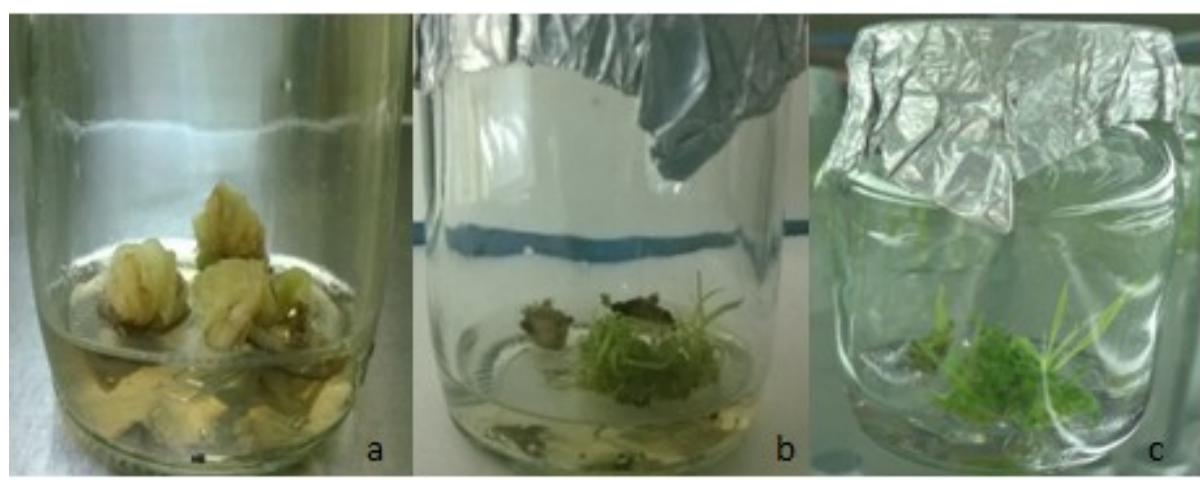

Figure 2: Different stages of direct plant regeneration a) Swelling and initiation of embryolike structures in ex-plants. b) Direct shoot regeneration. c) Prominent small shoots 
served after 4 weeks of the culture only in the medium D1 which contained 2,4-D $(0.5 \mathrm{mg} /$ L), IAA ( $1 \mathrm{mg} / \mathrm{L})$ and Kinetin $(0.1 \mathrm{mg} / \mathrm{L})$ and along with Cysteine Hydrochloride $(40 \mathrm{mg} / \mathrm{L})$. The development of embryo-like structures was observed at the third week after the cultures were transferred from dark conditions to light conditions. During the fourth week of culture in the above medium, the cultured leaf segments exhibited direct shoot regeneration (Figure 2b), and at the age of 5 weeks, prominent shoots (Figure 2c) were observed. Absence of callus formation in the ex-plants in this medium indicated direct regeneration of shoots.

The percentage success of the cultured explants with three weeks after culture is depicted in Figure 3. It is evident that the percentage success in the medium with 2,4-D $(0.5 \mathrm{mg} / \mathrm{L})$ and IAA $(1 \mathrm{mg} / \mathrm{L})$ continued to give values above 75 percent until the $8^{\text {th }}$ week after culture. The rest of the combinations showed a decline in culture success after 4 weeks of culture as shown in the graph below (Figure 3).

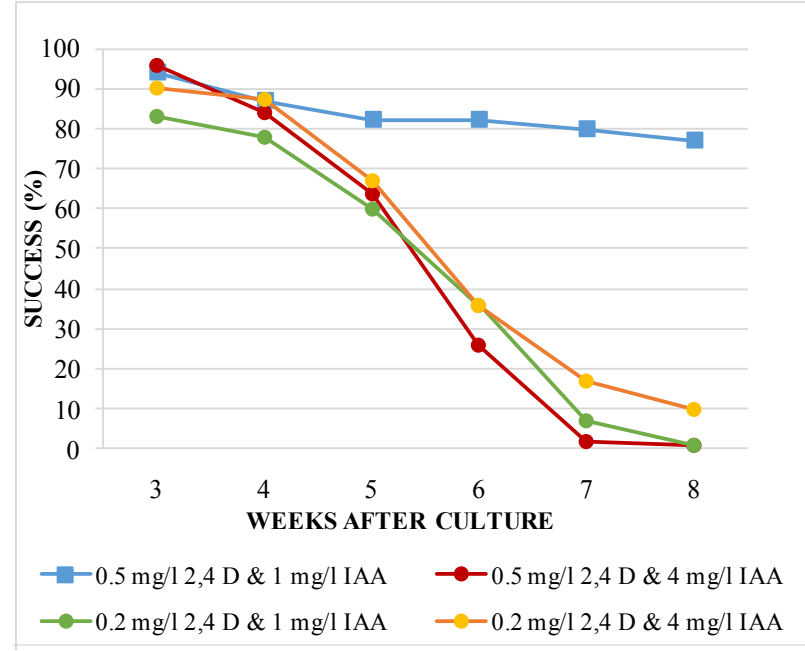

Figure 3: The percentage of success of cultured ex-plants with time

Accordingly, the best hormone combination identified in this study was $2,4-\mathrm{D}(0.5 \mathrm{mg} / \mathrm{L})$ and IAA $(1 \mathrm{mg} / \mathrm{L})$ with the fixed levels of $\mathrm{Ki}$ netin $(0.1 \mathrm{mg} / \mathrm{L})$ and IAA and Cysteine Hydrochloride $(40 \mathrm{mg} / \mathrm{L})$ with respect to direct shoot regeneration from ex-plants with high and prolonged success rates until the $8^{\text {th }}$ week in culture. Therefore, this hormone combination was found to be the only successful medium for direct regeneration of shoots from sugarcane leaf tissues. On average, 21 shoots were regenerated from a single ex-plant cultured in this medium while ex-plants of other combinations did not produce a single shoot. Mittal et al. (2013) and Ali et al. (2012), stated that MS media supplemented with NAA was the best media for the direct plant regeneration from spindle explants in sugarcane. In the present study NAA was eliminated because NAA induced rooting at very early stage. Direct plant regeneration can be advantageous since callus culture is associated with the problems in embryo formation, maturity and plantlet regeneration (Thorpe, 1994). In sugarcane, there are only a few reports dealing with direct regeneration of plants from different ex-plants (Gill et al., 2006) while there are literature available on regeneration and multiplication through organogenesis via callus culture that favours production of genetically-diverse plants. Direct adventitious shoot production occurred on the distal cut surface of the ex-plants and was found critical for maximum regeneration. Lakshmanan et al. (2006) reported that tissue polarity, the orientation of the ex-plant in the culture, size of the ex-plant and concentration of the growth regulators play significant roles in determining direct shoot regeneration superseding the callus phase. Therefore, future research should focus on the aforesaid aspects in the perfection of the protocol for direct regeneration of shoots from leaf tissues of sugarcane.

\section{CONCLUSIONS}

The modified Murashige and Skoog (MS) medium containing 2,4-D $0.5 \mathrm{mg} / \mathrm{L}$ and Kinetin $0.1 \mathrm{mg} / \mathrm{L}$ and IAA $1 \mathrm{mg} / \mathrm{L}$ along with Cysteine Hydrochloride $40 \mathrm{mg} / \mathrm{L}$ was found to be the best for direct shoot regeneration from sugar- 
cane leaf spindle tissues under the culture conditions adopted in this experiment. Further research is needed to fine tune the protocol by optimising culture conditions, ex-plant size and orientation of ex-plants in the culture.

\section{ACKNOWLEDGEMENT}

The authors are thankful to Dr. A P Keerthipala, Director/Chief Executive Officer of the Sugarcane Research Institute, Uda Walawe, for granting permission to carry out this research project at the Sugarcane Research Institute and for correction of the manuscript. The contribution of Dr Wasana Wijesuriya, Principal Research Officer (Biometry), Rubber Research Institute of Sri Lanka, Agalawatte, in statistical analysis of data is also acknowledged.

\section{REFERENCE}

Ali S, Khan MS and Iqbal J 2012 In vitro direct plant regeneration from cultured young leaf segments of sugarcane( Saccharum officinarum L). The journal of Animal and Plant Science, 22(4): 2012, page 1107-1112.

An Act to regulate the quality of seed and planting material: and to provide for matters connected therewith or incidental thereto acts 2003. Available at:http:// www.doa.gov.1k/images/stories/site/ PDF/Acts/seed\%20act.pdf (Accessed: 05 September 2016).

Anonymous 2015 Economic and Social Statistics of Sri Lanka 2015. Statistics Department Central Bank of Sri Lanka, Sri Lanka. pp 55.

Ehsanullah K, Jabran M, Jamil and Ghaffar A 2011 Optimizing the sugarcane row spacing and seeding density to improve its yield and quality. Crop Environ. 2: 15.
Gill R, Malhotra PK and Gosal SS 2006 Direct plant regeneration from cultured young leaf segments of sugarcane. Plant Cell Tissue Org. Culture, 84: 227-231.

Khan IA, Dahot MU, Seema N, Yasmeen, Bibi S, Raza G, and Khatri A and Naqvi MH 2009 Direct Regeneration of Sugarcane Plantlets: A Tool to Unravel Genetic Heterogeneity. Plant Breeding and Genetics Division, Nuclear Institute of Agriculture, Tando Jam 70060, Sindh, Pakistan.Pak. J. Bot., 41(2): 797-814.

Lakshmanan P, Geiskes RJ, Wang L, Elliott A, Grof CP L, Berding N and Smith GR 2006 Development and hormone regulation of direct shoot organogenesis and somatic embryogenesis in sugarcane (Saccharum spp. Interspecific hybrids) leaf culture. Plant Cell Reports, 25: 1007 $-1015$.

Mittal P, Devi R and Gosal SS 2013 Direct Plant Regeneration from Spindle Leaf Roll Explants in Sugarcane. Indian Journal of Ecology 40 (1): 67-70.

Thorpe TA, 1994 In vitro Embryogenesis in Plants. Current Plant Science and Biotechnology in Agriculture, Kluwer, Boston MA, 1995; vol. 20.

Viswanathan R, 2016 Varietal Degeneration in Sugarcane and its Management in India. Sugar Tech, 18(1), pp.1-7.

Wijesuriya A, Ariyawansha BDSK, Keerthipala AP and Sunil HK 2001 Rapid Propagation of Sugarcane throughLateral Shoot Multiplication (Japanese Method): Feasibility under Sri Lankan Conditions. Journal of the National Institute in Plantation Management. 17(1): 68-86. 